\title{
O EFEITO DO CUSTO DA TERRA NA RENTABILIDADE FLORESTAL: UM ESTUDO DE CASO PARA SANTA CATARINA
}

\author{
Ricardo Berger ${ }^{1}$, Anadalvo Juazeiro dos Santos ${ }^{1}$, Romano Timofeiczyk Júnior ${ }^{1}$, \\ Alexandre Muzy Bittencourt ${ }^{2}$, Vanderlei Santos de Souza ${ }^{3}$, Cristiane de Loyola Eisfeld ${ }^{4}$ \\ ${ }^{1}$ Eng. Florestal, Dr., Depto. de Economia Rural e Extensão, UFPR, Curitiba, PR, Brasil - berger@bighost.com.br; ajsantos@ufpr.br; \\ romano@ufpr.br \\ ${ }^{2}$ Eng. Florestal, M.Sc., Doutorando em Engenharia Florestal, UFPR, Curitiba, PR, Brasil - alexbitten@terra.com.br \\ ${ }^{3}$ Eng. Florestal, M.Sc., Consultor Florestal Brasil Timber, São Paulo, SP, Brasil - vanderlei.souza@ braziltimber.com \\ ${ }^{4}$ Eng ${ }^{a}$ Florestal, M.Sc., STCP Eng. de Projetos Ltda., Curitiba, PR, Brasil - criseisfeld@ hotmail.com \\ Recebido para publicação: 23/03/2009 - Aceito para publicação: 19/05/2011
}

\begin{abstract}
Resumo
Este trabalho objetivou verificar o impacto do custo da terra na rentabilidade da produção de madeira de Pinus. O setor florestal tem como característica fundamental gerar retornos financeiros em longo prazo, tornando muitas vezes o investimento na atividade um grande entrave a novos negócios. O preço da terra é uma variável que depende do retorno da atividade florestal, tornando necessário conhecer o efeito que o valor desse recurso terá sobre a rentabilidade. Para realizar uma estimativa da rentabilidade na atividade florestal, foram utilizados os critérios econômicos Valor Presente Líquido (VPL) e a Taxa de Interna de Retorno (TIR). Os resultados obtidos mostraram ser mais atrativa a não aquisição da terra, com VPL de US\$ 5.584,00 e TIR de $18 \%$ ao ano. Já quando foi considerada a compra da terra, os resultados econômicos sofreram redução, com VPL de US\$3.711,00 e TIR de 11\% ao ano. A opção de arrendamento apresentou VPL de US\$ $3.531,00$ e TIR de 13\% ao ano. Porém, antes de utilizar esses critérios como tomada de decisão, outros fatores devem ser avaliados, como o impacto da renda da reserva legal, melhor grau de utilização das terras e um manejo florestal adequado, visando aumentar a receita com a obtenção de novos produtos e maior produção das florestas.

Palavras-chave: Rentabilidade econômica; preço da terra; manejo florestal; pínus.
\end{abstract}

\begin{abstract}
The effect of land cost in the forest profitability: a case study for Santa Catarina. This research aimed to ascertain the impact of land cost land on profitability of Pinus spp. timber production. The forestry sector has as key feature to generate financial returns in the long term, often making the investment activity in a large barrier to new business. The price of land is a variable that depends on the return of forest activity, making it necessary to know the effect that the cost of this resource will have on profitability. In order to estimate return on forest activity, it uses economic criteria, like Net Present Value (NPV) and Internal Rate of Return (IRR). The results proved to be more attractive the nonacquisition of land, with NPV of US\$ 5.5804,00 and IRR of 18\% per year. Considering the investment in land (purchase or lease), the economic results have suffered reduction with NPV of US\$3.711,00 and IRR of $11 \%$ per year. The lease of land presented a NPV of US\$3.531,00 and IRR of $13 \%$ per year. But, before using such criteria as the only decision making, other factors must be evaluated as to obtain the income of the legal reserve, the better level of use of land and a proper forest management, aiming to increase revenue with the acquisition of new products and increased production of forests.

Keywords: Economic profitability; land price; forest management; pinus.
\end{abstract}

\section{INTRODUÇÃO}

Para a realização da atividade florestal, são necessários investimentos em uma série de recursos de produção, como, por exemplo, o custo em termos de imobilização de terra, equipamentos e operação. O conhecimento desses custos é crucial para o planejamento e a administração, bem como de extrema importância para se conhecer a eficiência econômica do empreendimento. 
O uso de critérios de análise econômica na área florestal faz-se necessário para se decidir qual a melhor alternativa a ser adotada. Entre os principais critérios existentes, podemos citar: Valor Presente Líquido (VPL), Taxa Interna de Retorno (TIR), Razão Benefício/Custo (B/C), Valor Anual Equivalente (VAE), Custo de Oportunidade da Terra (COT), Valor Esperado da Terra (VET) e Custo Médio de Produção (CMP).

Com a utilização de algumas dessas ferramentas, Dossa et al. (2001), em um estudo de caso em Santa Catarina, verificaram que o retorno econômico da atividade florestal foi bastante expressivo, com um VPL de R \$ 31.337,30 e TIR variando de $6 \%$ a $21 \%$, de acordo com os cenários analisados. Outro estudo nesse sentido foi desenvolvido por Dossa et al. (2002) em empresas florestais paranaenses e catarinenses, no qual também verificaram a viabilidade econômica da produção de Pinus com TIR de $11 \%$ ao ano quando comparada à taxa mínima de atratividade de $6 \%$ considerada pelos autores.

Além dos tradicionais critérios de análise de investimentos, na atividade florestal há o uso de outros critérios de avaliação, como o Valor Esperado da Terra (VET), desenvolvido inicialmente por Martin Faustmann em 1849. Esse autor criou o método para determinar o preço máximo de compra da terra nua a ser utilizada para determinada cultura, no caso a florestal. Como ele considerou o horizonte de planejamento infinito, vem sendo amplamente aplicado também em análises de projetos florestais e na seleção de alternativas de manejo florestal (SILVA et al., 2005). A fórmula proposta do VET é a simples expressão da soma do valor presente das receitas líquidas obtidas no final de ciclos de produção florestal que se repetem perpetuamente.

A terra é o capital básico de qualquer produtor florestal, sendo de relativa permanência e representando um alto investimento (TIMOFEICZYK JÚNIOR et al., 2007). Em função disso, estudos relacionados ao custo da terra tornam-se relevantes, pois permitem auxiliar nas tomadas de decisões de investidores e na formulação de políticas de governo para esses setores.

Pode-se afirmar que, para uma boa rentabilidade florestal, a escolha da terra para a atividade deve estar calcada em três alicerces: preço, produtividade e aproveitamento. $\mathrm{O}$ investidor deve possuir o conhecimento dessas três variáveis antes de qualquer decisão sobre investimentos em terras para o cultivo florestal. Apesar de o valor pago pela terra estar sendo remunerado a uma taxa de juros até o final do período, o seu investimento inicial é o maior dispêndio realizado pelo investidor. Nesse sentido, analisar projetos florestais de viabilidade econômica sem considerar o valor pago pela terra recai em um grave equívoco.

O critério do VET é um instrumental que pode ser aplicado também quando se pretende verificar o valor máximo que se deve pagar pela terra, oferecendo mais uma ferramenta para o gestor planejar suas ações de médio e longo prazo no estabelecimento de florestas. Quanto maior o aproveitamento e a produtividade do site ou sítio, provavelmente maior será o preço da terra, valor este compensado nas receitas advindas da produção.

O custo de oportunidade da terra é o custo alternativo ou o retorno que poderia ser obtido caso os investimentos em terra fossem aplicados em outra alternativa. Uma vez que os investimentos em terra para a utilização florestal são em geral elevados, esse custo se torna muito importante na avaliação econômica da empresa florestal (RODRIGUES et al., 1999).

Pereira e Rezende (1983) mencionam que o custo de oportunidade da terra representa aproximadamente $5 \%$ do custo total de produção florestal no Brasil, sendo que o percentual pode aumentar de acordo com o valor das terras. Se considerarmos ainda que as áreas de preservação permanente e de reserva legal não poderiam ser utilizadas para produção de madeira, o custo da terra pode chegar a $15 \%$ ou mais do custo de produção, dependendo da topografia ou particularidade da região (SILVA et al., 2008).

Esse fato pode estar se refletindo em uma tendência de decréscimo na área plantada por algumas empresas em terras próprias. De acordo com a Associação Brasileira de Produtores de Florestas Plantadas (ABRAF), ocorreu entre 2006 e 2007 uma redução de $2 \%$ nos plantios em áreas próprias por parte das empresas associadas, ao mesmo tempo em que nesse mesmo período houve um aumento nos plantios de $18 \%$ em áreas fomentadas e $14 \%$ em áreas arrendadas (ABRAF, 2008).

Uma das razões para essa tendência é que, não havendo investimento em terra e optando-se pelo arrendamento, a empresa obtém uma rentabilidade maior do investimento na atividade florestal. Nesse sentido, o presente trabalho objetivou avaliar o impacto do preço da terra na viabilidade econômica de plantios florestais, bem como verificar a contribuição do manejo florestal sustentável da Reserva Legal como alternativa para o incremento das receitas na propriedade. 


\section{MATERIAIS E MÉTODOS}

\section{Dados utilizados}

Para o presente estudo de viabilidade econômica, foram utilizadas informações primárias sobre custos, investimentos, produtividade e preços obtidos junto a empresas do setor florestal localizadas no Planalto Central Catarinense no período de agosto de 2007. Todos os valores estão em dólar, de acordo com a base de dados macroeconômicos, financeiros e regionais do Brasil, mantida pelo Instituto de Pesquisa Econômica Aplicada (IPEA, 2008).

Tais informações referem-se a florestas de Pinus spp. com espaçamento 3 x $2 \mathrm{~m}$, representativas para as empresas consultadas da região. O regime de manejo considerado constitui-se de uma rotação de 20 anos com duas intervenções (desbastes), aos 8 e 12 anos. A estrutura média das áreas de cultivos florestais da região tem a seguinte distribuição, para cada 100 ha: 20 ha de Reserva Legal, 10 ha de Área de Preservação Permanente, 5 ha de Benfeitoria e 3 ha de Áreas Inaproveitáveis. As características silviculturais e de manejo adotadas estão de acordo com o padrão utilizado pelas empresas da região.

O preço unitário da madeira em pé, obtido junto ao Centro de Socioeconomia e Planejamento Agrícola (CEPA), é apresentado na tabela 1. Para fornecer valores mais próximos da realidade, eles estão divididos por sortimento, de acordo com as finalidades exigidas pelo mercado industrial madeireiro catarinense.

Tabela 1. Preço da madeira em pé (US $\left.\$ / \mathrm{m}^{3}\right)$.

Table 1. Price of standing timber $\left(\mathrm{US} \$ / \mathrm{m}^{3}\right)$.

\begin{tabular}{lc}
\hline Sortimento & $\mathbf{U S \$ / \mathbf { m } ^ { \mathbf { 3 } }}$ \\
\hline Serraria 1 - S1 & 39 \\
Serraria 2 - S2 & 64 \\
Laminação - LM & 90 \\
\hline
\end{tabular}

Fonte: Instituto CEPA (2008).

A produtividade dos plantios estudados foi dividida, assim como os preços, de acordo com a finalidade da madeira. Com o auxílio da ferramenta SisPinus, desenvolvida pela Embrapa Florestas, as produtividades de acordo com o sortimento são apresentadas na tabela 2.

Tabela 2. Produtividade média dos plantios de Pinus spp. na região do Planalto Central Catarinense.

Table 2. Average productivity of Pinus spp. in the Central Plateau region of Santa Catarina State.

\begin{tabular}{lccc}
\hline Sortimento & 8 anos & 12 anos & 20 anos \\
\hline Celulose - C1 & 63 & 40 & 139 \\
Serraria 1 - S1 & - & 47 & 124 \\
Serraria 2 - S2 & - & 31 & 155 \\
Laminação - LM & - & - & 33 \\
\hline Total & 63 & 118 & 451 \\
\hline Fonte: Sispinus - Embrapa. Elaborado pelos autores. & &
\end{tabular}

\section{Cenários propostos}

Visando verificar a variação no retorno do investimento (TIR e VPL) no cultivo de Pinus spp. no Planalto Central Catarinense, foram estabelecidos os seguintes cenários:

a) Fluxo de caixa sem a inclusão do preço de aquisição da terra

Esse cenário é proposto apenas para verificar o impacto que a aquisição ou o arrendamento da terra para o cultivo de florestas causa no retorno do investimento, pois é sabido que mesmo na atividade florestal a terra apresenta custo de oportunidade em relação à agricultura, pecuária ou mesmo outros usos florestais. Sendo assim, a pressuposição de que a terra só tem valor para a produção de madeira não possui aporte teórico e nem prático, pois, se não há uso alternativo para a terra, então seu custo de oportunidade é zero (REZENDE; OLIVEIRA, 2001).

b) Fluxo de caixa com a inclusão do custo de aquisição da terra

A premissa para esse cenário é de que a terra é um fator de produção como qualquer outro e deve

FLORESTA, Curitiba, PR, v. 41, n. 3, p. 599-610, jul./set. 2011. 
ser remunerado e compor os custos de produção. Sendo assim, adotou-se o valor de mercado da terra para a análise, considerando a opção do investidor em imobilizar o capital nesse recurso durante o ciclo de produção florestal.

c) Fluxo de caixa com a inclusão do aluguel/arrendamento da terra

Considerando que na opção de não investir capital em terra evita-se a imobilização do valor investido na aquisição desse fator, a opção foi a de arrendar a terra para o cultivo florestal.

\section{Fluxo de caixa}

O fluxo de caixa representa as projeções de custos e receitas dos recursos financeiros investidos em determinado projeto ao longo do tempo. Para uma melhor percepção do comportamento do fluxo de caixa, seus valores são atualizados para um único momento no tempo, através de fórmulas financeiras de desconto de juros (SANTOS; PAIVA, 2002).

Para o presente trabalho, foram elaborados os fluxos de caixa para os três cenários propostos, objetivando avaliar o impacto do custo da terra no investimento florestal para cultivo de Pinus spp. em Santa Catarina.

\section{Métodos de análise de investimentos}

Após a obtenção do fluxo de caixa contendo as entradas e saídas monetárias ao longo do horizonte de planejamento, foram utilizadas ferramentas da engenharia econômica para avaliação da rentabilidade do manejo. Todos os valores estimados neste trabalho correspondem ao hectare produtivo de terra, ou seja, quanto será a rentabilidade do produtor com base na sua produção por cada hectare de terra. Para esclarecer melhor esse conceito, usaremos como medida o Grau de Utilização da Terra (GU). Neste estudo, dentre os vários métodos existentes, utilizou-se o Valor Presente Líquido (VPL) e a Taxa Interna de Retorno (TIR).

\section{Valor Presente Líquido (VPL)}

Expresso em valores monetários e largamente utilizado para medir a eficiência econômica de um investimento, é obtido através da soma algébrica dos valores descontados do fluxo de caixa para o início do investimento, segundo a taxa mínima de atratividade adotada. De acordo com Rezende e Oliveira (2001), o VPL pode ser expresso pela seguinte fórmula:

$$
V P L=\sum_{j=0}^{n} R j(1+i)^{-j}-\sum_{J=0}^{n} C j(1+i)^{-j}
$$

em que: $\mathrm{Rj}=$ receitas no período de tempo $\mathrm{j}$ considerado;

$\mathrm{Cj}=$ custos no período de tempo $\mathrm{j}$ considerado;

$\mathrm{n}$ = duração do projeto em anos ou em número de períodos de tempo;

i = taxa anual de juro, expressa de forma decimal.

\section{Taxa Interna de Retorno (TIR)}

Expresso de forma percentual, a TIR é um dos critérios econômicos mais utilizados para medir e comparar a eficiência de investimentos florestais. A TIR é alcançada quando o VPL do fluxo de caixa se iguala a zero, ou seja, quando o somatório das receitas menos os custos for igual a zero, então a taxa de juros “i”corresponderá à TIR. Por fornecer a real rentabilidade do investimento, ela é considerada a taxa interna do empreendimento, e segundo Rezende e Oliveira (2001) pode ser obtida pela seguinte fórmula:

$$
V P L=\sum_{j=0}^{n} R j(1+i)^{-j}-\sum_{j=0}^{n} C j(1+i)^{-j}=0
$$

em que: $\mathrm{Rj}=$ receitas do período de tempo $\mathrm{j}$ considerado;

$\mathrm{Cj}=$ custos do período de tempo $\mathrm{j}$ considerado;

$\mathrm{n}=$ duração do projeto em anos ou em número de períodos de tempo. 


\section{Taxa Mínima de Atratividade (TMA)}

De acordo com Lima Jr. et al. (1997), as taxas de juros para analisar projetos florestais no Brasil situam-se entre 6 e $12 \%$ ao ano. Para este estudo, a TMA utilizada para descontar os valores do fluxo de caixa foi de $7 \%$. Seu valor é arbitrado de acordo com a disposição do produtor, gestor ou proprietário em aceitar um investimento de risco ao invés de retorno certo num investimento de baixo risco no mercado financeiro.

\section{Valor Esperado da Terra (VET)}

Tem como princípio atribuir à terra o excedente econômico da produção florestal. Esse excedente gerado no final da rotação é trazido para o início do investimento, considerando-se, no entanto, a possibilidade de a terra ser devotada de forma perpétua para a produção de madeira (BERGER, 2009).

em que: VET = Valor Esperado da Terra;

$$
V E T=\frac{\sum_{j=0}^{n}\left[(R j-C j)(1+i)^{n-1}\right]}{(1+i)^{n}-1}
$$

$\mathrm{Rj} \quad=$ receitas líquidas descontadas;

$\mathrm{Cj}=$ custos totais descontados;

$\mathrm{i} \quad=$ taxa de desconto;

$\mathrm{n} \quad$ = idade de rotação da floresta.

Para que ocorra um excedente econômico, a TIR do investimento florestal deve ser maior do que a TMA. Assim, o excedente passa a ser o quanto pode ser gasto para se adquirir a terra ou o valor máximo que se pode gastar nela e ainda permitir a remuneração dos fatores e do proprietário (BERGER, 2009).

\section{Grau de Utilização da Terra (GUT)}

Grau de Utilização da Terra é a relação percentual entre a área efetivamente utilizada (AEU) pela atividade rural e a área aproveitável (AAI) do imóvel rural. Diferentemente de áreas urbanas, as propriedades rurais possuem muitas restrições quanto ao seu uso para produção. As áreas de Reserva Legal (RL), Área de Preservação Permanente (APP), Benfeitorias (Bf) e Inaproveitáveis (In) podem representar mais de $50 \%$ da área total da propriedade. Isso significa que, para o proprietário rural possuir 1 ha de terra produtiva, será necessário no total a aquisição de 1,5 hectares de terra.

De acordo a Instrução Normativa ${ }^{\circ} 11$ do Instituto Nacional de Colonização e Reforma Agrária (INCRA) (2003), em seu artigo $5^{\circ}$, o Grau de Utilização da Terra é obtido conforme a relação:

$$
G U T=\left(\frac{A E U}{A A I}\right) \times 100
$$

em que: GUT = Grau de Utilização da Terra;

AEU $=$ área efetivamente utilizada ${ }^{1}$;

AAI = área aproveitável do imóvel ${ }^{2}$.

\section{RESULTADOS E DISCUSSÃO}

\section{Fluxo de caixa}

As tabelas 3, 4 e 5 mostram os fluxos de caixa da atividade por hectare, onde estão apresentados os valores para o custo total (C.T./ha), receita total (R.T./ha) e receita líquida (R.L./ha), estimados com base na produtividade e preço da madeira em pé. As tabelas 3, 4 e 5 representam, respectivamente, os fluxos de caixa para os três cenários propostos $(\mathrm{a}, \mathrm{b}, \mathrm{c})$.

\footnotetext{
${ }^{1} \mathrm{AEU}=$ Área efetivamente utilizada, aquela que se encontra de acordo com o conceito de função social da propriedade. No caso em exame, tem-se especial destaque ao cumprimento da legislação ambiental, que está diretamente ligada ao grau de produtividade e eficiência do imóvel.

${ }^{2}$ AAI = Área aproveitável do imóvel, que, nos termos do art. $7^{\circ}$, é calculada subtraindo-se a área não aproveitável da área total. Áreas não aproveitáveis, por sua vez, de acordo com o art. $6^{\circ}$, são:

(i) ocupadas com construções e instalações, excetuadas aquelas destinadas a fins produtivos;

(ii) comprovadamente imprestáveis à exploração;

(iii) sob efetiva exploração mineral;

(iv) protegidas por legislação ambiental e as de efetiva preservação permanente.
}

FLORESTA, Curitiba, PR, v. 41, n. 3, p. 599-610, jul./set. 2011. 
Tabela 3. Fluxo de caixa do investimento florestal por hectare, sem o custo da terra.

Table 3. Cash flow of investment per hectare forest, without the cost of land.

\begin{tabular}{|c|c|c|c|c|}
\hline Atividade & Ano & $\begin{array}{c}\text { C.T. } \\
\text { (US\$/ha) }\end{array}$ & $\begin{array}{c}\text { R.T. } \\
\text { (US\$/ha) }\end{array}$ & $\begin{array}{c}\text { R.L. } \\
\text { (US\$/ha) }\end{array}$ \\
\hline Custo de implantação & 0 & 976 & - & $(976)$ \\
\hline Manutenção/Roçada/Combate a formiga & 1 & 172 & - & $(172)$ \\
\hline Manutenção/Roçada/Combate a formiga & 2 & 170 & - & $(170)$ \\
\hline Manutenção/Roçada/Combate a formiga & 3 & 164 & - & $(164)$ \\
\hline Manutenção & 4 & 42 & - & $(42)$ \\
\hline Manutenção/Poda & 5 & 194 & - & (194) \\
\hline Manutenção & 6 & 42 & - & $(42)$ \\
\hline Manutenção & 7 & 194 & - & (194) \\
\hline Manutenção & 8 & 42 & 882 & 840 \\
\hline Manutenção & 9 & 42 & - & (42) \\
\hline Manutenção & 10 & 42 & - & (42) \\
\hline Manutenção & 11 & 42 & - & (42) \\
\hline Manutenção & 12 & 42 & 4.377 & 4.335 \\
\hline Manutenção & 13 & 42 & - & (42) \\
\hline Manutenção & 14 & 42 & - & (42) \\
\hline Manutenção & 15 & 42 & - & (42) \\
\hline Manutenção & 16 & 42 & - & (42) \\
\hline Manutenção & 17 & 42 & - & (42) \\
\hline Manutenção & 18 & 42 & - & (42) \\
\hline Manutenção & 19 & 42 & - & (42) \\
\hline Manutenção & 20 & 42 & 19.672 & 19.630 \\
\hline Total & & 2.500 & 24.931 & 22.431 \\
\hline
\end{tabular}

Fonte: Elaborado pelos autores.

Tabela 4. Fluxo de caixa do investimento florestal por hectare, com a compra da terra.

Table 4. Cash flow of investment per hectare forest, with the purchase of land.

\begin{tabular}{|c|c|c|c|c|}
\hline Atividade & Ano & $\begin{array}{c}\text { C.T. } \\
\text { (US\$/ha) }\end{array}$ & $\begin{array}{c}\text { R.T. } \\
\text { (US\$/ha) } \\
\end{array}$ & $\begin{array}{c}\text { R.L. } \\
\text { (US\$/ha) } \\
\end{array}$ \\
\hline Custo de implantação e de aquisição da terra & 0 & 3.501 & - & $(3.501)$ \\
\hline Manutenção/Roçada/Combate a formiga & 1 & 172 & - & $(172)$ \\
\hline Manutenção/Roçada/Combate a formiga & 2 & 170 & - & $(170)$ \\
\hline Manutenção/Roçada/Combate a formiga & 3 & 164 & - & $(164)$ \\
\hline Manutenção & 4 & 42 & - & $(42)$ \\
\hline Manutenção/Poda & 5 & 194 & - & $(194)$ \\
\hline Manutenção & 6 & 42 & - & $(42)$ \\
\hline Manutenção & 7 & 194 & - & $(194)$ \\
\hline Manutenção & 8 & 42 & 882 & 840 \\
\hline Manutenção & 9 & 42 & - & (42) \\
\hline Manutenção & 10 & 42 & - & (42) \\
\hline Manutenção & 11 & 42 & - & (42) \\
\hline Manutenção & 12 & 42 & 4.377 & 4.335 \\
\hline Manutenção & 13 & 42 & - & (42) \\
\hline Manutenção & 14 & 42 & - & (42) \\
\hline Manutenção & 15 & 42 & - & (42) \\
\hline Manutenção & 16 & 42 & - & $(42)$ \\
\hline Manutenção & 17 & 42 & - & (42) \\
\hline Manutenção & 18 & 42 & - & (42) \\
\hline Manutenção & 19 & 42 & - & (42) \\
\hline Manutenção & 20 & 42 & 22.197 & 22.155 \\
\hline Total & & 5.025 & 27.456 & 22.431 \\
\hline
\end{tabular}

Fonte: Elaborado pelos autores. 
Tabela 5. Fluxo de caixa do investimento florestal por hectare, com o arrendamento da terra.

Table 5. Cash flow of investment per hectare forest, with the lease of land.

\begin{tabular}{lccccc}
\hline Atividade & Ano & $\begin{array}{c}\text { C.T. } \\
\text { (US\$/ha) }\end{array}$ & $\begin{array}{c}\text { Arrendamento } \\
\text { (US\$/ha) }\end{array}$ & $\begin{array}{c}\text { R.T. } \\
\text { (US\$/ha) }\end{array}$ & $\begin{array}{c}\text { R.L. } \\
\text { (US\$/ha) }\end{array}$ \\
\hline Custo de implantação & 0 & 976 & 177 & - & $(1.153)$ \\
Manutenção/Roçada/Combate a formiga & 1 & 172 & 177 & - & $(348)$ \\
Manutenção/Roçada/Combate a formiga & 2 & 170 & 177 & - & $(346)$ \\
Manutenção/Roçada/Combate a formiga & 3 & 164 & 177 & - & $(340)$ \\
Manutenção & 4 & 42 & 177 & - & $(219)$ \\
Manutenção/Poda & 5 & 194 & 177 & - & $(371)$ \\
Manutenção & 6 & 42 & 177 & - & $(219)$ \\
Manutenção & 7 & 194 & 177 & - & $(371)$ \\
Manutenção & 8 & 42 & 177 & 882 & 663 \\
Manutenção & 9 & 42 & 177 & - & $(219)$ \\
Manutenção & 10 & 42 & 177 & - & $(219)$ \\
Manutenção & 11 & 42 & 177 & - & $(219)$ \\
Manutenção & 12 & 42 & 177 & 4.377 & 4.158 \\
Manutenção & 13 & 42 & 177 & - & $(219)$ \\
Manutenção & 14 & 42 & 177 & - & $(219)$ \\
Manutenção & 15 & 42 & 177 & - & $(219)$ \\
Manutenção & 16 & 42 & 177 & - & $(219)$ \\
Manutenção & 17 & 42 & 177 & - & $(219)$ \\
Manutenção & 18 & 42 & 177 & - & $(219)$ \\
Manutenção & 19 & 42 & 177 & - & $(219)$ \\
Manutenção & 20 & 42 & 177 & 19.672 & 19.453 \\
\hline Total & & 2.500 & 3.717 & 24.931 & 18.714 \\
\hline Fonte: Elaborado pelos autores. & & & & &
\end{tabular}

A tabela 3 apresenta o fluxo de caixa para o cenário que não inclui o valor de aquisição da terra no fluxo de caixa.

As primeiras receitas advêm do primeiro desbaste aos 8 anos. Aos 12 anos, as receitas aumentam em função da produção de madeiras com maiores diâmetros, destinadas a serraria e laminação, as quais apresentam valores de mercado superiores. O corte raso ocorre aos 20 anos, com substancial incremento da receita total.

Dessa forma, o fluxo de caixa da tabela 3 representa os custos e receitas apenas do empreendimento florestal, não considerando, assim, custos com a terra, seja pelo valor de aquisição ou qualquer tipo de pagamento pelo seu uso, como aluguel ou arrendamento. Já na tabela 4 incorpora-se no fluxo de caixa a aquisição da terra no início do cultivo (cenário b). No ano zero observa-se o custo de implantação (US\$ 1.986,00) somado ao custo de aquisição da terra (US\$ 1.515,00)

$\mathrm{O}$ investimento na aquisição da terra para plantio de Pinus em Santa Catarina entra como custo no ano zero. Nesse cenário, ao final do ciclo de produção de madeira de 20 anos adotado neste trabalho, a terra entra como receita somada à receita advinda do corte raso da floresta. Essa premissa tem como base a negociação para venda da terra após o cultivo florestal.

A tabela 5 apresenta o fluxo de caixa para o cenário que considera o aluguel/arrendamento da terra.

Para esse cenário, a alternativa é o arrendamento da terra destinada ao plantio de Pinus. Entretanto, há uma grande dificuldade em se definir qual o valor a ser cobrado para esse arrendamento, pois pode ser tanto um valor de mercado predeterminado para a região quanto um valor proporcional à receita líquida advinda de outras atividades na região. O valor do arrendamento está baseado na expectativa de remuneração da atividade florestal, considerando que o proprietário da terra receberá uma remuneração à taxa de desconto no mínimo igual à da atividade a que destinou suas terras.

Para cada hectare plantado com Pinus, são necessários 1,67 hectares de área bruta, considerando um aproveitamento de $60 \%$. Dessa forma, com um valor de US\$ $1.515,00$ por hectare de área bruta, o valor do hectare para o cultivo florestal será de US\$ 2.525,00 (Tabela 6). Uma taxa de desconto de 7\% utilizada como mínima para assumir o investimento e que incide sobre o valor do hectare utilizável de terra gera $\mathrm{R} \$ 177,00$ por hectare por ano. 
Tabela 6. Grau de utilização da terra nas empresas florestais consultadas.

Table 6. Degree of land use in forestry companies consulted.

\begin{tabular}{lcc}
\hline Descrição & Área (ha) & \% \\
\hline Terra & 100 & 100 \\
Reserva Legal & 20 & 20 \\
A.P.P. & 12 & 12 \\
Infraestrutura & 3 & 3 \\
Inaproveitável & 5 & 5 \\
Área Produtiva & 60 & 60 \\
Grau de Utilização & \multicolumn{2}{c}{1,67 ha bruto } \\
1 ha líquido & \multicolumn{2}{c}{ US\$ 1.515 } \\
Preço efetivo da terra & \multicolumn{2}{c}{} \\
\hline Fonte: Elaborado pelos autores.
\end{tabular}

Fonte: Elaborado pelos autores.

\section{Análise de investimento}

A análise de investimento deste estudo baseia-se, como já mencionado anteriormente, na situação de uso da terra em algumas empresas florestais catarinenses. Nesse sentido, antes de iniciar a análise econômica, há a necessidade de se obter o verdadeiro valor do preço da terra, baseado no Grau de Utilização (GU) das mesmas.

Para as opções com investimento da terra ocorrendo no início da análise ("b") e como alternativa o aluguel/arrendamento ("c"), torna-se necessário o cálculo do GU, pois o valor do hectare produtivo sofre grande influência desse parâmetro. A partir dessas informações, o valor do GU estimado foi de $60 \%$, ou seja, para cada 100 ha de terra, o produtor tem capacidade de produzir em apenas 60 ha. Assim, seguindo esse conceito, pode-se definir que para cada 1 ha de terra plantado o produtor rural necessitará adquirir 1,67 ha de terra bruta (Tabela 6).

Considerando o preço médio do hectare de terra na região de US\$1.515,00 (CEPA, 2007), com um GU de 60\%, o produtor rural arca com um preço efetivo de US\$2.525,00 para produzir em 1 hectare de terra. No caso da opção por arrendamento (cenário "c") a uma TMA de 7\% ao ano, o custo anual será de US\$177/ha/ano.

A tabela 7 apresenta os indicadores econômicos calculados para diferentes opções de investimentos, no caso, relacionados à compra ou não da terra. Fica evidente o impacto do custo da terra na rentabilidade do investimento florestal. Os três projetos estudados mostraram-se viáveis de acordo com os critérios econômicos adotados, todos com VPL maior que zero e TIR maior que a TMA aceita. Entretanto, para um estudo do impacto do custo da terra, é preciso uma análise individual dos critérios encontrados para cada uma das opções de investimento em terra.

Tabela 7. Resultados econômicos dos cenários propostos.

Table 7. Economic results of the proposed sceneries.

\begin{tabular}{|c|c|c|c|c|}
\hline Critério & Ud & $\begin{array}{c}\text { Não aquisição da } \\
\text { terra (a) }\end{array}$ & $\begin{array}{c}\text { Com aquisição da } \\
\text { terra (b) }\end{array}$ & $\begin{array}{c}\text { Com arrendamento } \\
\text { da terra (c) }\end{array}$ \\
\hline Valor Presente Líquido & US\$/ha & 5.584 & 3.711 & 3.531 \\
\hline Valor Esperado da Terra & US\$/ha & 7.529 & 7.529 & 7.529 \\
\hline Taxa Interna de Retorno & $\%$ & 18 & 11 & 13 \\
\hline \multicolumn{5}{|l|}{ Custo Unitário da Madeira } \\
\hline Celulose - C1 & $\mathrm{US} \$ / \mathrm{m}^{3}$ & 4 & 9 & 8 \\
\hline Serraria 1 - S1 & $\mathrm{US} \$ / \mathrm{m}^{3}$ & 10 & 24 & 21 \\
\hline Serraria 2 - S2 & $\mathrm{US} \$ / \mathrm{m}^{3}$ & 17 & 39 & 35 \\
\hline Laminação LM & $\mathrm{US} \$ / \mathrm{m}^{3}$ & 24 & 55 & 49 \\
\hline
\end{tabular}

Fonte: Elaborado pelos autores.

De acordo com a tabela 7, os indicadores econômicos apresentam-se atraentes para o investidor que não optar pela compra da terra, com TIR de $18 \%$ a.a., bem acima dos $13 \%$ a.a. para a opção que considera o arrendamento. Porém deve-se ressaltar que o usuário da terra deve pagar uma "renda ou 
retorno pelo uso da terra", composto pelo juro sobre o capital investido nesse recurso de produção, expresso como custo de oportunidade pelo uso do capital (BERGER, 1985).

Apesar da dificuldade peculiar do uso do Valor Presente Líquido (VPL) para comparar projetos com horizontes de planejamento diferentes, aqui podem ser perfeitamente utilizados, pois se trata do mesmo projeto para o mesmo horizonte de planejamento. O VPL para a opção de não aquisição de terra ("a") foi de US\$ 5.584,00, valor acima dos US\$ 3.711,00 e US\$ 3.531,00 para as opções de aquisição ("b") e arrendamento da terra ("c"), respectivamente.

Apesar de muito utilizado para mensurar a rentabilidade de projetos florestais, o VPL tem seus resultados expressos em valores absolutos. Dessa forma, a TIR muitas vezes é preferível ao método do VPL, por expressar seus valores em taxas percentuais, possibilitando a comparação entre projetos similares e mesmo entre diferentes tipos de investimentos financeiros.

Para o presente estudo, a opção pela aquisição da terra obteve a menor TIR entre os investimentos, com um valor de $11 \%$, mostrando que o investimento com arrendamento da terra é uma opção mais rentável que esta, com uma TIR de $13 \%$.

A TIR maior para o arrendamento em comparação à aquisição da terra pode ser explicada pelo valor que representa a saída de caixa no ano zero para cada uma das duas opções. Enquanto que para o arrendamento, de acordo com a opção "c", a saída de capital é de US\$1.153,00, para a aquisição em terra o valor correspondente à saída de caixa é de US\$ 3.501,00. Para o período até o sexto ano, ou seja, o resultado do fluxo de caixa antes de qualquer receita, a opção "c" tem um saldo negativo de US\$ 3.367,00, contra, para o mesmo cálculo da opção "b", um valor a maior de US\$ 1.112,00.

Outra avaliação importante a ser feita quando da opção por investimentos em plantios florestais é o cálculo do custo de produção da madeira - um método simples, porém eficaz, na tomada de decisão, pois o custo para produzir um metro cúbico de madeira deve ser inferior ao preço de mercado do mesmo. Assim, quanto menor esse valor, maior será o retorno financeiro da atividade. De acordo com a tabela 7 , pode-se verificar que o custo unitário da madeira para a opção de não aquisição da terra ("a") foi a menor entre as opções estudadas. Porém, como já mencionado anteriormente, devemos considerar o valor pago pelo preço da terra, seja na aquisição ou no arrendamento.

Para as duas opções de investimento em terras estudadas, a de arrendamento mostrou ser a mais atrativa quanto ao custo da madeira. Considerando que as receitas líquidas descontadas até o $11^{\circ}$ ano foram de US\$ 3.765,00 e US\$ 3.361,00, respectivamente, para as opções "b" e "c", os valores para custo de produção de madeira em pé foram diferentes para cada um dos cenários. De acordo com a tabela 7, a opção de arrendamento da terra, tendo como base o cenário "c", mostrou valores menores de produção, o que a torna, de acordo com esse critério, mais vantajosa economicamente.

Além da TIR e do VPL, o conceito de VET é outro fator importante para ser considerado em uma análise financeira de investimentos florestais. Uma das grandes preocupações do administrador florestal é saber quanto pode pagar por uma área de terra, com o objetivo de reflorestá-la. Assim, deve-se determinar o VET para posteriormente compará-lo com o preço de mercado da terra onde se pretende implantar uma floresta. A tabela 8 mostra os valores para o VET de acordo com o tipo de investimento, obtidos a partir das informações apresentadas na tabela 2 .

O VET é o valor da expectativa do solo e representa o valor presente da receita líquida que a terra proporciona, em perpetuidade, a cada horizonte de planejamento. Consequentemente, representa o preço máximo que se pode pagar por um hectare de terra nua, a fim de que o reflorestamento seja economicamente viável (SILVA et al., 2008). A partir desse raciocínio, e de acordo com esse critério, é viável economicamente o cultivo de Pinus com os valores pagos pelo hectare de US\$1.515,00/ha, pois o VET mostra que o investimento é viável nessas condições até US\$ 7.529,00 pagos para cada hectare de terra.

Um dos grandes desafios dos produtores florestais é a maximização de suas receitas, sendo uma das alternativas em crescente uso nos cultivos florestais o manejo sustentável da Reserva Legal (RL). Essa prática apresenta-se como uma alternativa para aumentar a área produtiva, possibilitando um incremento na rentabilidade do investimento florestal. Considerando, a título de simulação, que o ganho líquido da RL seja de US\$ 59/ha/ano produtivo e aplicando esse novo incremento na receita do investimento, verifica-se um expressivo aumento da rentabilidade do investimento. A tabela 8 apresenta os resultados simulados de acordo com a incorporação dessa receita. 
Tabela 8. Resultados econômicos dos cenários propostos com a inclusão da receita proveniente da Reserva Legal.

Table 8. Economic results of the proposed sceneries by the inclusion of revenue from the Legal Reserve.

\begin{tabular}{lcccc}
\hline Critério & Ud & $\begin{array}{c}\text { Não aquisição da } \\
\text { terra (a) }\end{array}$ & $\begin{array}{c}\text { Com aquisição da } \\
\text { terra (b) }\end{array}$ & $\begin{array}{c}\text { Com arrendamento } \\
\text { da terra (c) }\end{array}$ \\
\hline Valor Presente Líquido & US\$ha & 6.209 & 4.336 & 4.156 \\
Valor Esperado da Terra & US\$ha & 8.372 & 8.372 & 8.372 \\
Taxa Interna de Retorno & $\%$ & $20 \%$ & $12 \%$ & $14 \%$ \\
\hline Fo & & & &
\end{tabular}

Fonte: Elaborado pelos autores.

Os resultados alcançados após a inclusão da receita líquida do manejo da Reserva Legal mostram aumentos substanciais no retorno economico da atividade se comparados aos resultados sem essa opção. Isso representa em média um aumento de US\$ 625 no VPL, US\$ 843 no VET e 1,3\% na TIR.

O manejo da Reserva Legal possibilita, além de um ganho financeiro para o produtor florestal, um ganho ambiental para a sociedade. Em razão do atual estágio avançado de degradação da maioria das reservas florestais no país, a possibilidade de manejo nessas áreas tende a promover o enriquecimento da vegetação nativa sob Reserva Legal em projetos florestais.

\section{CONCLUSÕES}

- A metodologia proposta permite uma análise do impacto do custo da terra na rentabilidade da produção florestal, considerando três opções de investimento para o produtor rural. Verificou-se que a inclusão da terra nas análises econômicas influenciou o retorno econômico da atividade florestal, com variações de até $28 \%$ na TIR e $37 \%$ no VPL entre os cenários analisados.

- Quando o investimento florestal é avaliado somente sob a ótica da floresta, independente da terra, os retornos financeiros mostram-se mais atrativos. Porém, raciocínios como esse tendem a superestimar os parâmetros de avaliação florestal, dando ao investimento um falso retorno econômico. A terra é essencial para o cultivo florestal, sendo indispensáveis os recursos financeiros para sua aquisição ou arrendamento/aluguel.

- Avaliar o Grau de Utilização da terra é fundamental para qualquer planejamento florestal, visto que as áreas com restrição à utilização para produção podem chegar a mais de $50 \%$ do total da propriedade. Isso causa um impacto muito grande na rentabilidade, uma vez que o investidor paga pelo total da área adquirida, mas a produção fica restrita a apenas parte dela.

- O incremento das receitas provenientes da reserva legal apresentadas a título de exemplo nesse trabalho servem como base para negócios alternativos e/ou complementares à base atual de renda dos pequenos produtores rurais. O uso sustentável da Reserva Legal traz benefícios para o produtor, pois, além de um incremento em suas receitas, propicia a manutenção de fauna e flora locais e melhoria na qualidade da água, entre outros benefícios ambientais. A partir do momento em que se obtém lucro financeiro com a preservação, a sua prática torna-se mais constante, auxiliando assim na preservação de ecossistemas naturais. Com os lucros provenientes da Reserva Legal, o investimento obteve um ganho de $1 \%$ na TIR nos cenários "b" e "c", passando esta a ser de $14 \%$ ao ano.

- De maneira geral, o estudo mostrou que para a região de estudo o arrendamento é melhor opção em termos de rentabilidade econômica da produção, retorno este que pode ser maximizado com o uso da reserva legal.

\section{REFERÊNCIAS}

ASSOCIAÇÃO BRASILEIRA DOS PRODUTORES DE FLORESTAS PLANTADAS (ABRAF). Anuário estatístico 2008. Disponível em: <http://www.abraflor.org.br/>. Acesso em: 10/06/2008.

BERGER, R. Aplicação de critérios econômicos para determinação da maturidade financeira de povoamentos de eucaliptos. $73 \mathrm{f}$. Tese (Professor titular) - Setor de Ciências Agrárias, Universidade Federal do Paraná, Curitiba, 1985. 

2. $142 \mathrm{p}$.

Economia florestal. In: Administração Estratégica da Produção. Curitiba: UFPR, 2009. módulo

CENTRO DE SOCIOECONOMIA E PLANEJAMENTO AGRÍCOLA (CEPA). Disponível em: <http://cepa.epagri.sc.gov.br/>. Acesso em: 05/06/2008.

DOSSA, D.; MONTOYA, L. J.; LUDWIG, M. Um estudo de caso: produção e mercado de Pinus. Colombo, 2001. Comunicado Técnico n. 53. Disponível em: <http://www.cnpf.embrapa.br /publica/com.untec/edicoes/com_tec53.pdf >. Acesso em: 09/09/2009.

DOSSA, D.; SILVA, H. D.; BELlOTE, A. F. J.; RODIGHERI, H. R. Produção e rentabilidade de Pinus em empresas florestais. Colombo, 2002. Comunicado Técnico n. 82. Disponível em: <http://www.cnpf.embrapa.br/publica/comuntec/edicoes/com_tec82.pdf >. Acesso em: 09/09/2009.

INSTITUTO NACIONAL DE COLONIZAÇÃO E REFORMA AGRÁRIA (INCRA). Instrução Normativa n. 11, de 04/04/2003. Estabelece diretrizes para fixação do Módulo Fiscal de cada Município de que trata o Decreto n..$^{\circ} 84.685$, de 6 de maio de 1980, bem como os procedimentos para cálculo dos Graus de Utilização da Terra - GUT e de Eficiência na Exploração GEE, observadas as disposições constantes da Lei n. ${ }^{\circ}$ 8.629, de 25 de fevereiro de 1993. Diário Oficial da União, Brasília, DF, 16 abr. 2003. Disponível em: <http://www.incra.gov.br/portal/index.php?option=com_docman\&task=search_ result\&It emid=141>. Acesso em: 19/01/2010.

LIMA JÚNIOR.; REZENDE, J. L. P.; OLIVEIRA, A. D. Determinação da taxa de desconto a ser usada na análise econômica de projetos florestais. Cerne, Lavras, n. 1, p. 45 - 66, 1997.

PEREIRA, A. R.; REZENDE, J. L. P. Situação atual dos reflorestamentos com incentivos fiscais no estado de Minas Gerais. Revista Culturas Energéticas Biomassa, São Paulo, v. 2, n. 5, p. 14 - 17, 1983.

REZENDE, J. L. P.; OLIVEIRA, A. D. Análise econômica e social de projetos florestais. Viçosa: UFV, 2001.

RODRIGUES, F. L.; LEITE, H. G.; SILVA, M. L.; GOMES, A. N. Determinação de estratégias ótimas de reforma, condução da brotação e compra de terras, utilizando programação linear. Árvore, Viçosa, v. 23, n. 2, p. 169 - 186, 1999.

SANTOS, M. J. C.; PAIVA, S. N. Os sistemas agroflorestais como alternativa econômica em pequenas propriedades rurais: estudo de caso. Ciência Florestal, Santa Maria, v. 12, n. 1, p. 135 - 141, 2002.

SILVA, M. L. da; REZENDE, J. L. P. de; LIMA JÚNIOR, V. B.; CORDEIRO, S. A.; COELHO JÚNIOR, L. M. Métodos de cálculo do custo da terra. Cerne, Lavras, v. 14, n. 1, p. $75-81,2008$. Disponível em: <http://www.dcf.ufla.br/cerne/artigos/10-02-20096470v14_n1_artigo\%2010.pdf〉. Acesso em: 04/09/2009.

SILVA, M. L.; FONTES, A. A. Discussão sobre os critérios de avaliação econômica: valor presente líquido (VPL), valor anual equivalente (VAE) e valor esperado da terra (VET). Árvore, Viçosa, v. 29, n. 6, p. 931 - 936. 2005.

SILVA, M. L.; PAIVA, H. N.; XAVIER, A. Diagnóstico e estudo de viabilidade técnica e econômica do reflorestamento com eucalipto na microrregião de Paracatu-MG. Viçosa: UFV, 2005. 85 p. Relatório técnico.

TIMOFEICZYK JÚNIOR, R.; BERGER, R.; SOUSA, R. A. T. M.; SILVA, V. S. M. 2007. Custo de oportunidade da terra no manejo de baixo impacto em florestas tropicais - um estudo de caso. Floresta, Curitiba, PR, v. 37, n. 3. 
FLORESTA, Curitiba, PR, v. 41, n. 3, p. 599-610, jul./set. 2011.

Berger, R. et al. 